\title{
Implementação do Controlador Repetitivo em um Processo para Compensar Distúrbios Periódicos
}

\author{
Rogério Passos do A. Pereira*, Ravena S. Monteiro*, Joabe R. Silva*, Marco Antônio de S. L. Cuandros*, \\ Gustavo M. de Oliveira*, Eduardo J. F. Andrade*, Teodiano Bastos**, \\ José Leandro F. Salles**, Raphael B. de S. Gomes*, Felipe da S. Paiva*. \\ *Grupo de Automação Industrial (GAIn), Coordenadoria de Engenharia de Controle e Automação, \\ Instituto Federal de Educação, Ciência e Tecnologia do Espirito Santo-Campus Serra, \\ Rodovia ES-010, KM 6.5, 29173-087, Manguinhos, Serra, ES, Brasil (e-mail: rogerio@ifes.edu.br, \\ ravena.soares@hotmail.com, joaberuella@gmail.com, cuandros@ifes.edu.br, gmaia@ifes.edu.br, \\ eduardo@ifes.edu.br, rapha.belizario@gmail.com, felipedasilvapaiva@gmail.com). \\ ** Prog.de Pós Graduação em Engenharia Elétrica, UFES - Universidade Federal do Espírito Santo, \\ Av. Fernando Ferrari, 214, 29.075-910, Goiabeiras, Vitória, ES, Brasil \\ (e-mail:teodiano.bastos@gmail.com, jleandro@ele.ufes.br)
}

\begin{abstract}
This work presents the practical implementation of an application using the repetitive controller in a first order plant to eliminate periodic disturbances. Repetitive control is useful if periodic disturbances act in industrial processes, such as energy systems and cyclic vibrations. The implemented control system presents a repetitive controller, using the discrete internal model, that is plugged in parallel to a classic PI controller. Rejection of disturbances is achieved if the time period is exactly known. Simulation and experimental results are provided to prove the effectiveness of repetitive control by compensating for periodic disturbances. Such control is a possible solution for steel processes that suffer from periodic disturbances such as continuous casting.
\end{abstract}

Resumo: Este trabalho apresenta a implementação prática de uma aplicação utilizando o controlador repetitivo em uma planta de primeira ordem, para eliminar distúrbios periódicos. O controle repetitivo é útil se perturbações periódicas atuam em processos industriais, como em sistemas de energia e vibrações cíclicas. O sistema de controle implementado apresenta um controlador repetitivo, usando o modelo interno discreto, que é plugado em paralelo a um controlador clássico PI. A rejeição de perturbações é alcançada se o período de tempo for exatamente conhecido. Simulação e resultados experimentais são fornecidos para comprovar a eficácia do controle repetitivo ao compensar distúrbios periódicos. Tal controle é uma possível solução para processos siderúrgicos que sofre com perturbações periódicas como o lingotamento contínuo.

Keywords: Repetitive Control, Periodic Disturbance, PI controller.

Palavras-chaves: Controle repetitivo, Distúrbio periódico, Controlador PI.

\section{INTRODUÇÃO}

Vários sinais encontrados na engenharia são periódicos ou podem ser aproximados para periódicos (Flores, 2012) e podem ser encontrados em sistema de potência e energia (Oliveira et al. 2013), em máquinas com tarefas repetitivas (Junior, 2014), em manipuladores robóticos (Oliveira et al. 2015) e em vibrações cíclicas em processos industriais. Devido ao crescimento exigido na produtividade e qualidade, esses processos que necessitam seguir setpoint periódico ou sofrem perturbações periódicas, torna-se um grande problema, pois os controladores clássicos, como o PI, não possuem ótimos desempenhos nestas situações (Flores, 2012).

Uma das soluções para o seguimento de referência ou compensação de distúrbio periódico em processos industriais são os controladores baseados no modelo interno (Francis \&
Wonham 1975). Um exemplo é o controle repetitivo, que pode funcionar como seguidor ou compensador de perturbações periódicas (Cruz, 2015). Para desempenhar sua função o controle repetitivo é plugado a um controlador principal. Assim, o controlador principal ficará responsável pela estabilização do processo, e para isso deve ser projetado para produzir uma resposta rápida (Gnoatto, 2011), já o controlador repetitivo trabalhará em paralelo com o controlador principal, com a finalidade de estabelecer erro nulo em regime permanente para referências e perturbações periódicas. Portanto, com a aplicação do controle repetitivo é possível garantir erro nulo em regime permanente e resposta dinâmica rápida em regime transitório, através do controlador principal (Oliveira et al., 2013).

Esse trabalho apresenta uma aplicação do controle repetitivo para compensar distúrbio periódico em um processo que possui característica de primeira ordem. 
$\mathrm{O}$ artigo está dividido em quatro seções, sendo que na primeira é apresenta a introdução, na segunda comenta-se a teoria básica do controle repetitivo. Na terceira seção são mostrados a simulação e a implementação prática do controlador e, finalmente, na última, os resultados $\mathrm{e}$ discussões são apresentados.

\section{CONCEITOS}

\subsection{Controle Repetitivo}

O controle repetitivo foi proposto por Hara et al. (1988) e por Tomizuka et al. (1989), são controles que possuem estruturas diferentes, dependendo da aplicação, mas sempre abordam sistemas que possuem características repetitivas (Kempf et al. 1993). Este método de controle analisa os erros de um período do sinal anterior e utiliza esses erros para calcular a ação de controle no período atual.

O controle repetitivo é uma técnica baseada no PMI (Princípio do Modelo Interno). Esse princípio estabelece que para se realizar o seguimento ou a rejeição de um determinado sinal é necessária a existência do modelo gerador desse sinal dentro do sistema de controle (Francis e Wonham, 1975).

O modelo gerador do sinal periódico que fica na estrutura desses controladores atribui ganho infinito ou muito elevado em uma determinada frequência e suas harmônicas para garantir que o sistema consiga reproduzir o sinal periódico e poder segui-lo, em forma de referência, ou rejeitá-lo, em forma de perturbação, com erro nulo em regime permanente.

A estrutura do modelo interno descrito tem como base aplicar um atraso em tempo discreto no sinal do erro. A função de transferência do modelo interno é apresentada em (1), onde o atraso na forma discreta $(N)$ é descrito em número de amostras. Para um período $(T)$ do sinal da perturbação ou da referência e um período de amostragem $\left(T_{s}\right)$, pode-se calcular $\mathrm{o}$ atraso (em amostras) do sinal periódico $\left(\mathrm{N}=\frac{T}{T_{s}}\right)$.

$$
G_{P}\left(z^{-1}\right)=\frac{z^{-N}}{1-z^{-N}}
$$

A dinâmica do controle repetitivo pode ser representada pelo diagrama de blocos da Figura 1. O sinal de erro (e) no instante (k) sofre um atraso de $(\mathrm{N})$ amostras e um ganho $\left(K_{r}\right)$, e, em seguida, é somado a ação de controle (N) amostras passadas, para calcular a ação de controle atual.

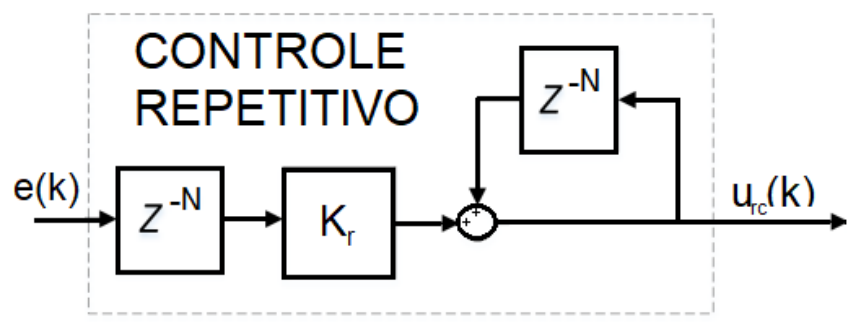

Figura 1. Diagrama de blocos do controle repetitivo.

\subsection{Controlador Proporcional Integral}

Os controladores de feedback são utilizados para atuar diretamente na variável do processo (V.P.) para uma variação de setpoint (Campos \& Teixeira, 2006). O controlador principal, que será usado neste trabalho, é o Proporcionalintegral (P.I.), pois é um controlador feedback que possui características de robustez ao compensar dinâmicas não previstas e pequenos distúrbios não periódicos no processo (Firmino, 2014), mas para compensar distúrbios periódicos o mesmo não possui a robustez necessária para obter erro nulo em regime permanente (Flores, 2015). Sua atuação é necessária para processos do tipo servo ou regulatório, pois garante o rastreamento da variável do processo a uma mudança de setpoint (Gnoatto, 2011).

Existem várias formas de sintonizar um controlador PI. Neste trabalho foi utilizado o método do modelo interno (IMC), pois é um método que calcula a sintonia do controlador com uma dinâmica de malha fechada em função do modelo do processo e de um critério de ajuste que determina quão rápido a variável do processo chega ao setpoint, definida pela constante de tempo desejada $(\lambda)$ para o sistema de malha fechada "H(s)", conforme representado em (3). Assim, calculando a sintonia utilizando o IMC é possível projetar o controlador principal com resposta dinâmica rápida em regime transitório. Tendo em vista tal critério e o modelo do sistema para uma resposta ao degrau, os ganhos do controlador, em (2) são calculados, conforme apresentado em Campos \& Teixeira (2006)

$$
\begin{aligned}
& G_{c}(s)=K_{c}\left(1+\frac{1}{s T_{i}}\right) \\
& H(s)=\frac{1}{\lambda s+1} \times e^{-t_{0} s}
\end{aligned}
$$

\subsection{Representação do processo de primeira ordem}

A planta física utilizada para teste foi um circuito eletrônico resistivo-capacitivo (R.C.), que é um sistema de primeira ordem, que devido a sua facilidade de implementação, pode substituir processo de primeira ordem, como planta de nível.

$\mathrm{Na}$ simulação do circuito eletrônico foi substituído pelo modelo de primeira ordem, conforme a função de transferência em (4), com a mesma constante de tempo do circuito eletrônico usada para os testes práticos.

No modelo do circuito RC tem-se a constante de tempo $(\tau)$, o ganho do processo $(K)$ e o atraso de transporte $\left(t_{0}\right)$, conforme mostra a função de transferência no domínio de Laplace, em (4). Para obter estes parâmetros é feito um teste prático aplicando um degrau unitário na planta $\mathrm{RC}$, e os parâmetros são medidos (calculados).

$$
G(s)=\frac{K}{\tau s+1} \times e^{-t_{0} s}
$$




\section{SIMULAÇÃO E IMPLENTAÇÃO NO PROCESSO}

\subsection{Sistema desenvolvido}

A Figura 2 apresenta o diagrama de blocos do controle repetitivo, onde mostra o controlador principal, neste caso o PI, e o controlador repetitivo, trabalhando em paralelo (plugado) para obtenção de um sinal de controle único, que é aplicado na planta. Assim, cada controlador atuará fazendo sua função específica, isto é, o PI, faz o processo seguir o setpoint com resposta dinâmica rápida no regime transitório, e o controlador repetitivo faz a compensação (eliminação) do distúrbio periódico $(d)$, em regime permanente.

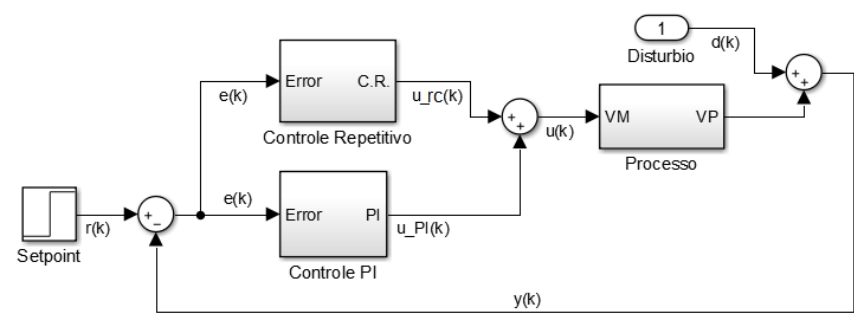

Figura 2. Diagrama de blocos do controlador repetitivo plugado ao controlador PI.

Para implementar o controle repetitivo foi utilizado o software LabVIEW $W^{\text {『 }}$ para desenvolver o algoritmo, e também o sistema supervisório, Figura 3, onde é possível alterar parâmetros e visualizar os dados.

A variável manipulada (V.M.) está descrita em (5), onde a ação de controle do sistema " $\mathrm{u}(\mathrm{k})$ " depende do controlador repetitivo " $u_{r c}(k)$ " e do controlador PI " $u_{p i}(k)$ ". Usando a função de transferência do modelo interno, em (1), que, neste caso, é a função periódica que define o distúrbio, temos a dinâmica do sinal do controlador repetitivo " $u_{r c}(k)$ " em (6), onde " $N$ " é o número de amostra do período.

$$
\begin{aligned}
& u(k)=u_{r c}(k)+u_{p i}(k) \\
& u_{r c}(k)=u_{r c}(k-N)+K_{r} e(k-N)
\end{aligned}
$$

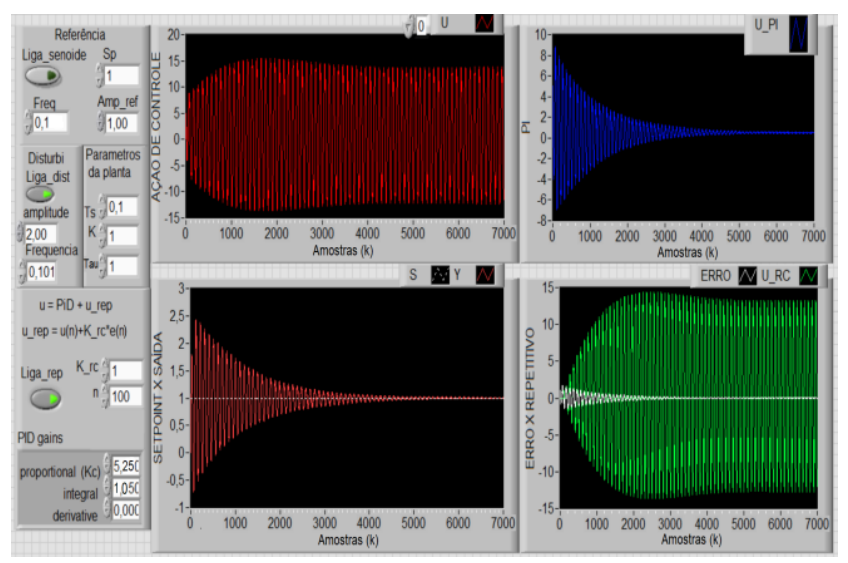

Figura 3. Sistema supervisório no LabVIEW $W^{\circledR}$.
A geração do distúrbio periódico foi criada no software LabVIEW ${ }^{\circledR}$, utilizando uma função que simula a onda senoidal com amplitude e frequência determinada através do sistema supervisório, conforme Figura 3.

\subsection{Simulação}

Primeiro foi definido o modelo de primeira ordem do processo desejado para a simulação, em (7). A partir do modelo do processo usando a tabela do método IMC foi calculada a sintonia do controlador conforme apresentado em Campos \& Teixeira (2006), com especificação de desempenho $(\lambda=0,2)$. Logo, obteve-se a função de transferência do controlador " $G_{c}(s)$ ", em (8).

$$
\begin{aligned}
& G(s)=\frac{1}{s+1} \times e^{-0,1 s} \\
& G_{c}(s)=5,25\left(1+\frac{1}{1,05 s}\right)
\end{aligned}
$$

A frequência e a amplitude do distúrbio senoidal gerado, como também o tempo de amostragem são apresentados na Tabela 1.

Tabela 1. Parâmetros do sistema.

\begin{tabular}{|c|c|}
\hline Frequência do distúrbio $\left(f_{d}\right)$ & $0,1(\mathrm{~Hz})$ \\
\hline Amplitude do distúrbio $(\mathrm{A})$ & $2(\mathrm{~V})$ \\
\hline Tempo de amostragem $\left(T_{s}\right)$ & $100(\mathrm{~ms})$ \\
\hline Número de amostra $(N)$ & 100 \\
\hline Ganho repetitivo $\left(K_{r}\right)$ & 1 \\
\hline
\end{tabular}

O Ganho repetitivo $\left(K_{r}\right)$ influencia no tempo que o erro fica nulo. Foi observado na simulação que o ganho unitário eliminou o erro com o tempo satisfatório nessa aplicação. $\mathrm{O}$ modelo da planta mostrada em (7), é discretizada pelo método segurador de ordem zero no tempo de amostragem de $100(\mathrm{~ms})$, somando com distúrbio "d(k)", obtém-se a saída "y" do sistema, em (9), para simular o processo.

$$
y(k)=0.905 y(k-1)+0.095 \mathrm{u}(k-1)+d(k)
$$

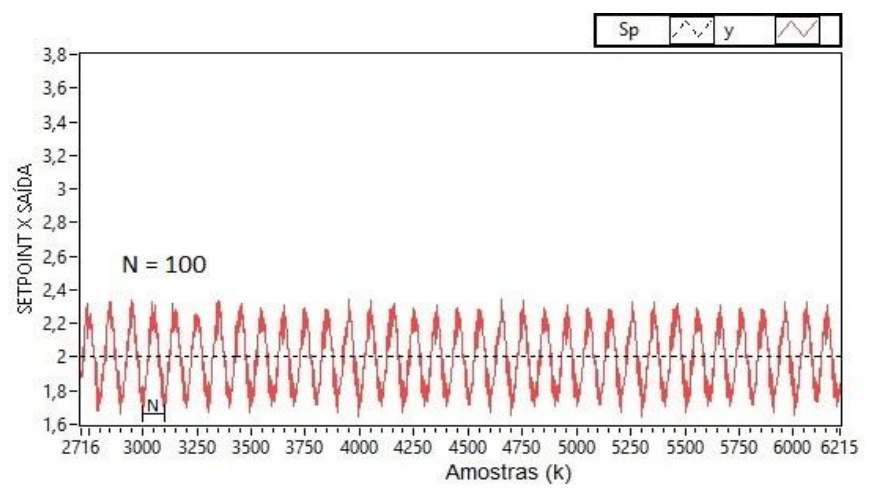

Figura 4. Saída do processo em malha fechada com distúrbio. 
A Figura 4 mostra a saída do processo com distúrbio em malha fechada com frequência de $0,1(\mathrm{~Hz})$, somente com o sinal de controle PI.

O simulador com controle repetitivo e a planta com distúrbio foi implementado e testado. Através da Figura 5 e da Figura 6, observa-se que inicialmente a saída do processo está oscilando, pois o controlador repetitivo não atua no mesmo instante que o distúrbio é aplicado. Passado um período do distúrbio, o sinal do controlador repetitivo começa a atuar lentamente até eliminar o distúrbio significativamente. A Figura 6 mostra o sinal de erro sendo atenuado e a ação de controle do controlador repetitivo.

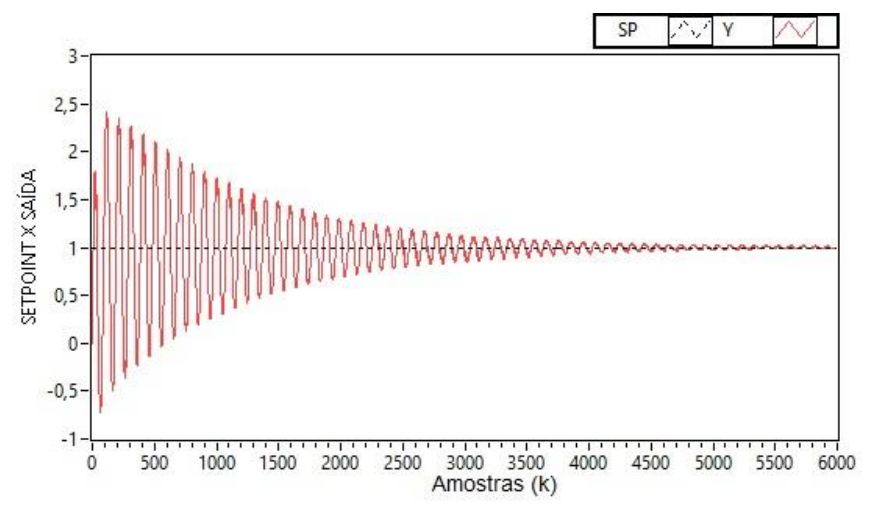

Figura 5. Resposta da saída "Y" em simulação para um distúrbio com frequência de $0,1(\mathrm{~Hz})$.

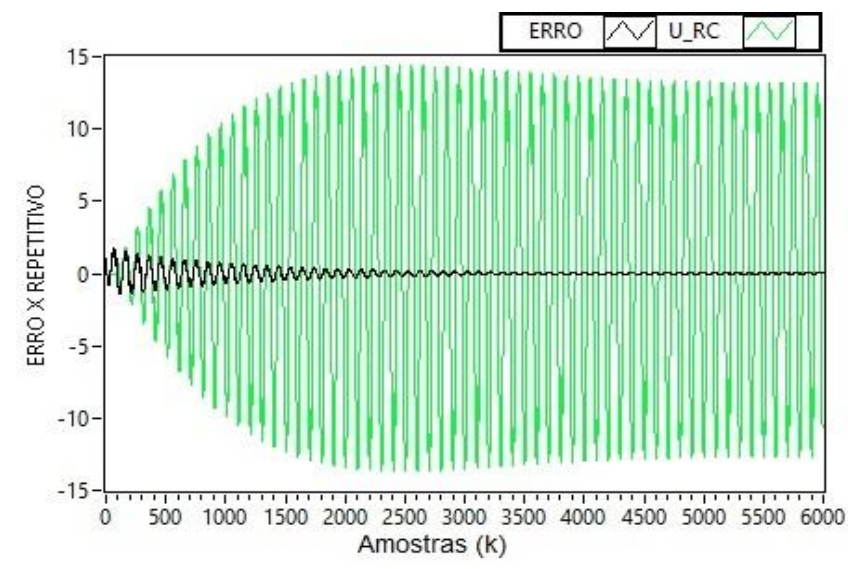

Figura 6. Sinal do erro comparando com a ação do controle repetitivo.

Comparando o tempo que a ação de controle repetitiva leva para alcança um valor significativo, aproximadamente a partir da amostra 2000 na Figura 6, conclui-se que traz benefício que a ação de controle repetitiva seja complementada com a ação de controle do PI.

Assim, como pode ser visto na Figura 7, a ação de controle aplicado efetivamente na planta, resultante da soma da ação de controle do PI com a ação de controle do repetitivo, adquire um valor significativo muito antes, aproximadamente a partir da amostra 1000, conforme Figura 7.

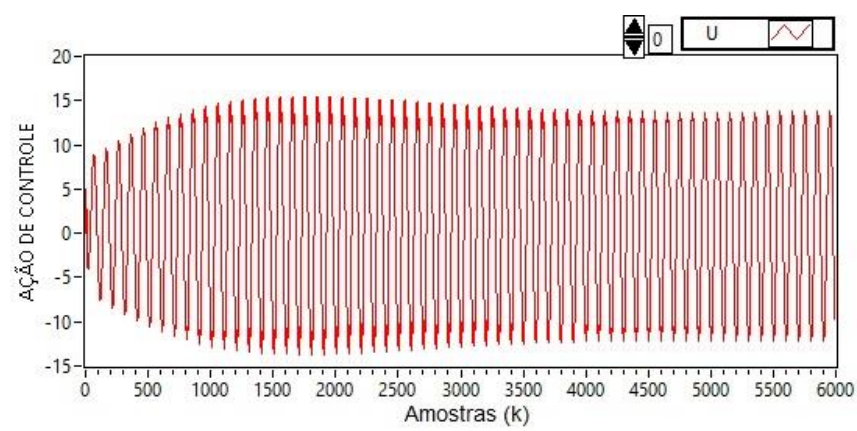

Figura 7. Sinal de controle (u).

\subsection{Aplicação prática}

$\mathrm{Na}$ aplicação prática foi usado o mesmo programa usado na simulação, porém foi substituído a expressão que defini o modelo, em (7), por um circuito RC, que fará o papel de uma planta de primeira ordem. Assim, a planta é constituída de um capacitor eletrolítico $(100 \mu \mathrm{F})$ e um resistor $(10 \mathrm{k} \Omega)$.

No esquema da Figura 8 mostra a interligação entre o computador, onde está o supervisório, o sistema embarcado NI myRIO da National Instruments, onde está instalado a aplicação, a planta, que é um circuito RC, e a interface, formada pelo circuito buffer e pelo circuito somador de sinais.

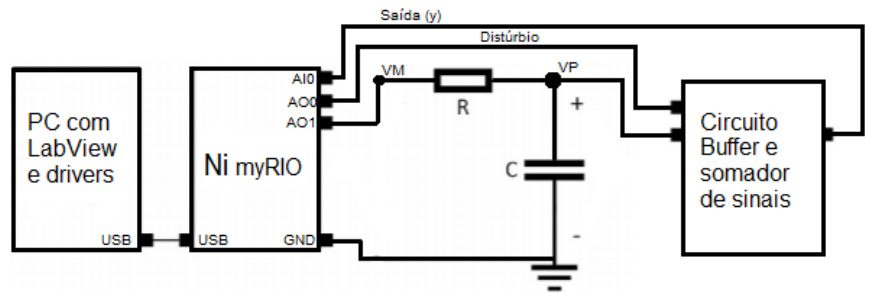

Figura 8. Esquema implementado.

A interface, Figura 9, é constituída de um circuito seguidor de tensão (buffer), primeiro amplificador operacional, para ajudar no casamento de impedância e um circuito somador não inversor, segundo amplificador operacional, para acoplar, juntar, a variável de processo (V.P.) com gerador de distúrbio (d).

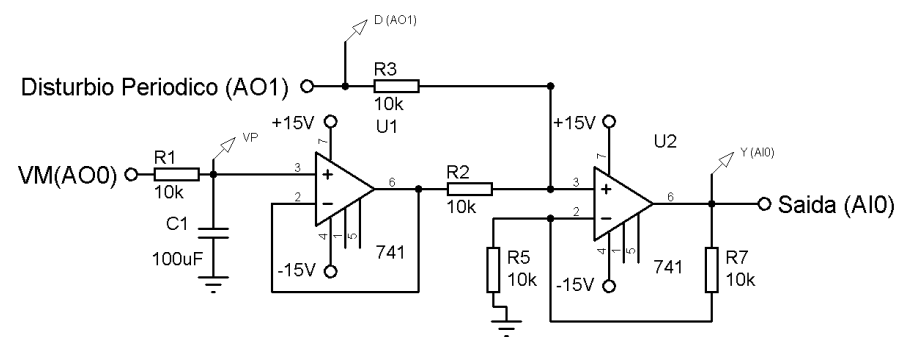

Figura 9. Interface formada por circuito buffer e circuito somador de sinais Circuito.

Os parâmetros do gerador de distúrbio utilizado no simulador foram os mesmos usados para gerar o distúrbio para os testes práticos. Conforme Tabela 1. 
Para confirmar que a planta implementada possuí o mesmo modelo da planta simulada, foi obtido o modelo da planta. Assim foi aplicando um degrau em malha aberta na planta, Figura 10. Com os dados obtidos foram calculados os parâmetros do modelo, onde ficou concluído que o modelo da planta prática ficou semelhante ao modelo do simulador, como era desejado. Os parâmetros do modelo da planta RC são apresentados na Tabela 2.

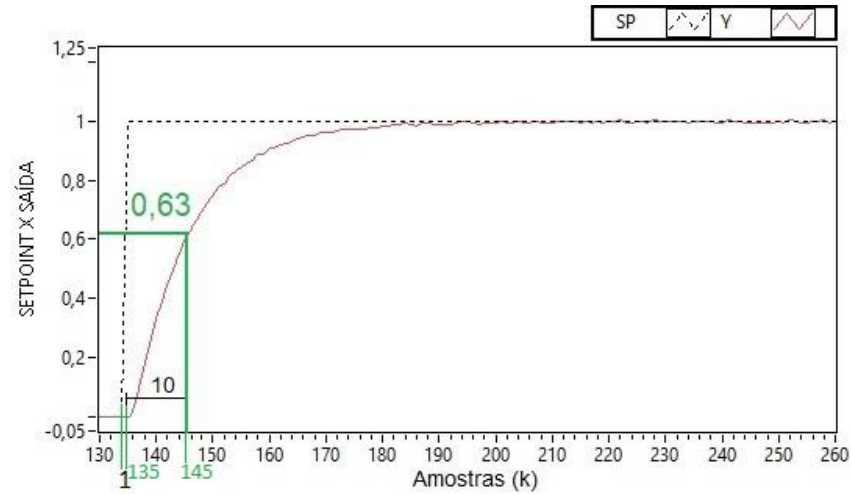

Figura 10. Na esquerda, a resposta ao degrau do sistema em malha aberta (M.A.).

Tabela 2. Testes práticos na planta $\mathrm{RC}$, obtido pela resposta ao degrau em malha aberta.

\begin{tabular}{|l|l|}
\hline Constante de tempo $(\tau)$ & $1,0(\mathrm{~s})$ \\
\hline Ganho $(K)$ & $1(\mathrm{~V})$ \\
\hline Tempo de atraso $\left(t_{0}\right)$ & $0,1(\mathrm{~s})$ \\
\hline
\end{tabular}

\section{RESULTADOS E DISCUSSÕES}

Os resultados dos testes práticos são apresentados na Figura 11 .

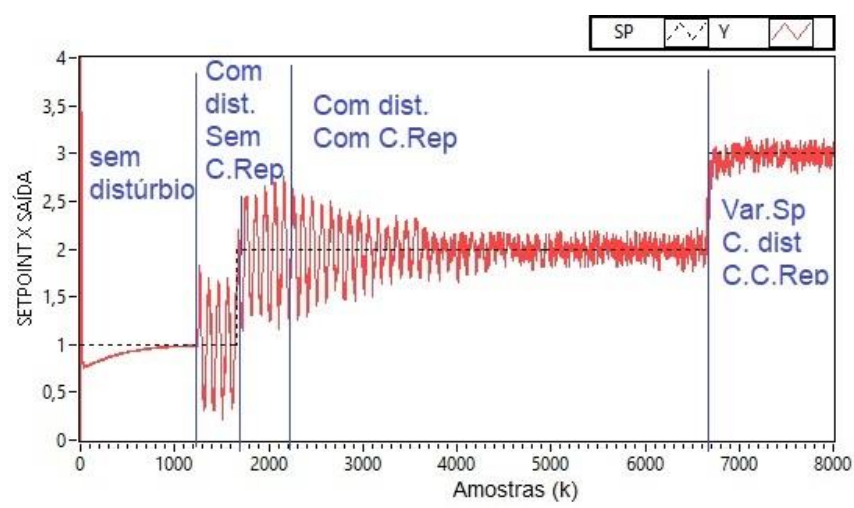

Figura 11. Resposta do processo (Y) com variação de setpoint.

Na Figura 11, foi aplicado na planta RC um setpoint de 1 (V), com o controlador PI. Após a amostra 1300 foi aplicado o distúrbio de amplitude de $2(\mathrm{~V})$ com frequência de $0,1(\mathrm{~Hz})$ e mantido o setpoint, porém o controlador PI não eliminou o distúrbio. Na amostra 1700 foi alterado o setpoint e mantido o distúrbio. O controlador PI corrigiu o erro em regime transiente para a variação de setpoint, mas não eliminou o distúrbio.

Na sequência, a partir da amostra 3000 foi aplicado o controlador repetitivo $\left(U_{R C}\right)$ no sistema, mantendo o PI. Assim, a oscilação começa a ser gradativamente atenuada pela ação de $U_{R C}$. Na sequência foi aplicado um setpoint de 3 (V) e a oscilação, devido ao distúrbio, continuou sendo atenuada pelo controle repetitivo, e o controlador PI atuou para diminuir o erro devido a variação de setpoint.

Fazendo uma análise do tempo de eliminação do distúrbio na Figura 12, conclui-se que são necessárias aproximadamente 3200 amostras da saída "Y" para o repetitivo compensar o distúrbio.

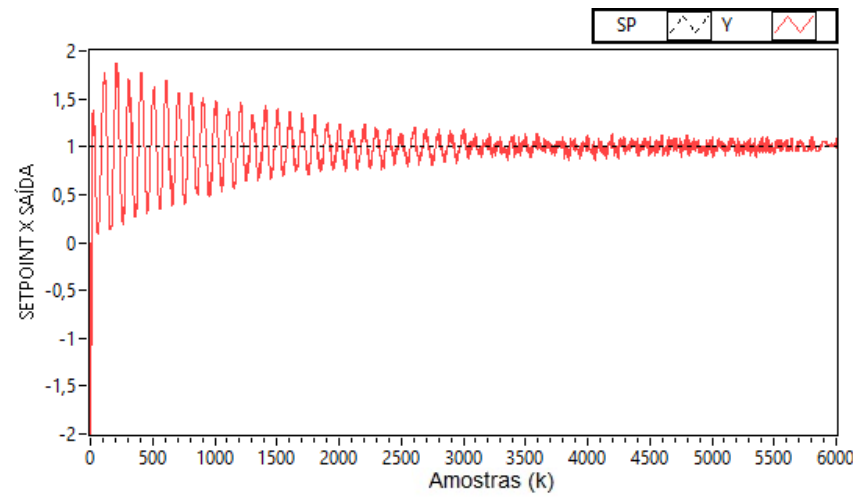

Figura 12. Saída do processo (Y) sem variação de setpoint para um distúrbio com frequência de $0,1(\mathrm{~Hz})$.

A Figura 13, mostra como a atuação de " $U_{R C}$ " é lenta mesmo sem variar o setpoint no processo, pois passou a ter valor significativo de atenuação a partir da amostra 3000 aproximadamente.

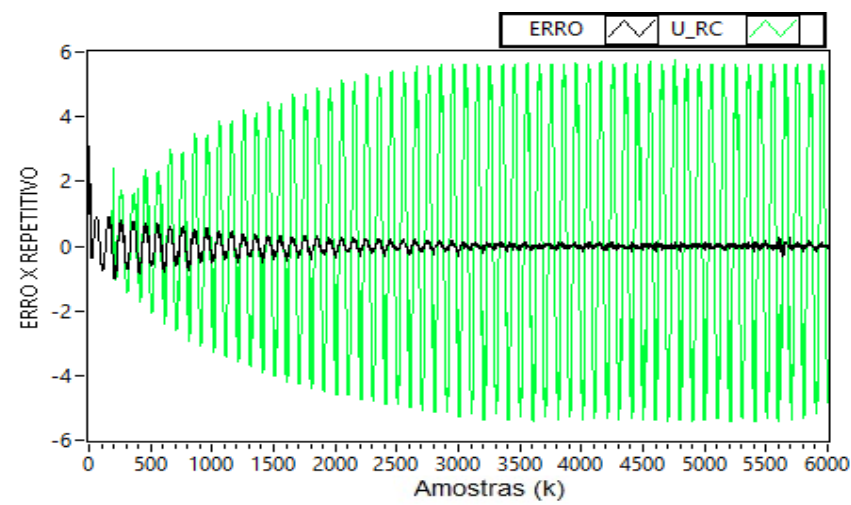

Figura 13. Comparação do sinal de erro com o sinal da ação do repetitivo no processo sem variação de setpoint.

Analisando a resposta do repetitivo com intuito de melhorar a sintonia, um ajuste é aumentar o ganho $\left(K_{r}\right)$ tornando a ação do repetitivo mais rápido, porém sempre evitando a saturação da variável manipulada.

Nessa aplicação o ganho $\left(K_{r}\right)$ unitário foi o melhor ajuste encontrado. 
A Figura 14 mostra que o sinal de controle total, "U", que é a soma da ação de controle do PI com a ação de controle do controlador repetitivo, adquire um valor significativo muito antes do sinal " $U_{R C}$ " devido a ação de controle PI que tem dinâmica rápida mesmo no processo sem variar o setpoint.

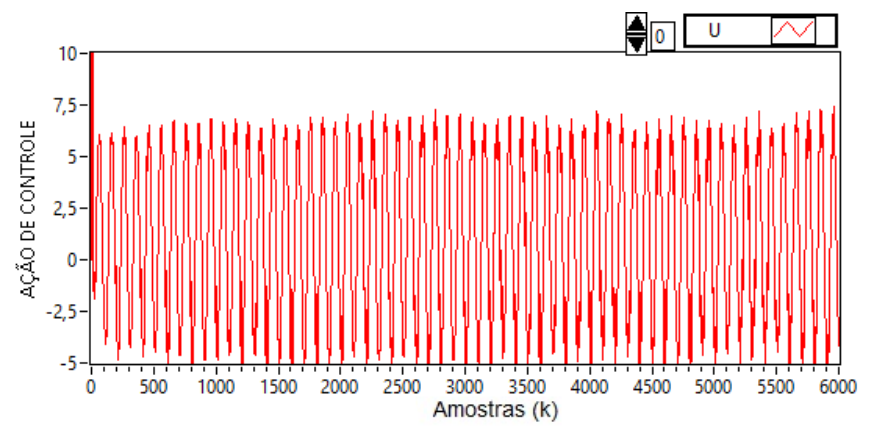

Figura 14. Sinal de controle (u) na implementação do processo no processo sem variação de setpoint.

O sinal de controle da Figura 14, foi relativamente alto para um distúrbio com amplitude de 2 (V), chegando a 5,5 volts no valor final do controle, devido ao ganho do repetitivo que atua no erro. Isso prejudica a ação de controle em atuadores com limites físicos (saturação), mas esse problema pode ser amenizado diminuindo o ganho $\left(K_{r}\right)$, tornando a ação do controlador repetitivo menos agressiva.

Uma grande dificuldade encontrada na implementação do controlador repetitivo foi a escolha da sintonia do PI que tivesse dinâmica rápida, mas que não prejudicasse a ação do repetitivo. Por esse motivo foi escolhido o método de sintonia IMC, pois nela específica a constante de tempo em malha fechada. Outra dificuldade foi gerar o sinal de distúrbio, que foi implementado criando o sinal em software pelo LabView e aplicando o mesmo no processo através da placa de aquisição NI myRIO.

\section{CONCLUSÕES}

O presente trabalho demostrou uma aplicação do controlador repetitivo para uma planta de primeira ordem, composta por um circuito RC, sendo a variável do processo (VP) a tensão em sobre o capacitor. $\mathrm{O}$ controle repetitivo implantado utiliza modelo interno, com o objetivo de eliminar perturbações periódicas, compostas por uma frequência fundamental e suas harmônicas.

Por possuir um atraso presente em sua estrutura, o controle repetitivo possui característica lenta. Para amenizar tal efeito, foi utilizado um controlador PI, que proporciona resposta dinâmica rápida. Para sintonia dos parâmetros da malha de controle foi utilizado o método IMC, para garantir uma resposta rápida no controlador principal.

Portanto, a aplicação do controlador repetitivo em paralelo com um controlador PI garantiu uma ótima resposta da planta, permitiu erro nulo em regime permanente e uma resposta transitória rápida no regime transitório.

Os dados obtidos na simulação e na implementação prática foram conclusivos, pois mostrou-se como o controle repetitivo pode ser robusto e útil para eliminação de distúrbios periódicos, mesmo quando o processo é submetido a uma variação de setpoint.

O controlador repetitivo apresentou a compensação do distúrbio periódico, mas deixou uma pequena oscilação, não periódica, devido aos outros pequenos distúrbios existentes no processo.

\section{AGRADECIMENTOS}

Agradecemos ao IFES, á UFES e ao grupo de pesquisa (Gain) pelo apoio concedido às pesquisas que deram origem ao presente trabalho.

\section{REFERÊNCIAS}

Campos, M. C. M. de, Teixeira, H. C. G. (2006). Controle Típicos de equipamentos e processos industriais. Petrobras. Editora Blucher. São Paulo, pp. 60-63.

Cruz, D. M. (2015). Estruturas de controle preditivo repetitivo baseadas na formulação GPC. Universidade Federal de Santa Catarina, Florianópolis.

Firmino, F. (2014). Estudo Comparativo em Métodos de Sintonia de Controladores PID. Universidade Federal de São Carlos, São Paulo.

Flores, J. V. (2012). Projeto de controladores para seguimento de referências periódicas em sistemas com atuadores saturantes. Universidade Federal do Rio Grande Sul, Porto Alegre.

Francis, B. A. and Wonham, W. M. (1975). The internal model principle for linear multivariable regulators, Appl. Math. Optimization, pp. 170-194.

Gnoatto, C. L. (2011). Estratégias de Controle Repetitivo para Aplicação em Sistemas de Alimentação Interrupta de Energia. Universidade Tecnológica Federal do Paraná, Paraná.

Junior, J. F. de B. (2014). Aplicação de Controladores Ressonantes e Repetitivos para Estabilização Lateral em Elevadores de Alta Velocidade. Universidade Federal do Rio Grande Sul, Porto Alegre.

Hara, S., Yamamoto, Y., Omata, T. and Nakano, M. (1988). Repetitive control system: A new type servo system for periodic exogenous signals, IEEE Trans. Autom. Contr., pp. 659-668.

Oliveira, A. F., Silva, S. M., Santos, C. H., \& Filho, B. d. (2013). Aplicação do controle repetitivo a inversor PWM monofásico com filtro LC de saída utilizado em fonte programável C.A., pp. 1161-1169.

Oliveira, I. G., Lages, W. F., \& Jr, J. M. (2015). Controle Repetitivo Aplicado a Manipuladores Robóticos para Rastreamento de Referência no Espaço Cartesiano, XII Simpósio Brasileiro de Automação Inteligente (XII SBAI), pp. 1-6.

Kempf, C., Messner, W., Tomizuka, M. (1993). Comparison of four discrete-time repetitive control algorithm, IEEE Contr. Syst. Mag., pp. 48-54.

Tomizuka, M., Tsao, T. C., Chew, K.-K. (1989). Analysis and synthesis of discrete-time repetitive controllers, Trans. ASME: J. Dyn. Syst., Meas., pp. 353-358. 